\title{
Feasibility and safety of watershed detection by contrast-enhanced ultrasound in patients receiving peripheral venoarterial extracorporeal membrane oxygenation: a prospective observational study
}

\author{
Nina Buchtele ${ }^{1}$, Thomas Staudinger ${ }^{1}$, Michael Schwameis ${ }^{2 *}$, Christian Schörgenhofer ${ }^{3}$, Harald Herkner $^{2}$, \\ Alexander Hermann ${ }^{1}$ and UltraECMO investigators
}

Keywords: Extracorporeal membrane oxygenation, Contrast media, Ultrasonography, Feasibility studies

\section{Background}

In bifemoral venoarterial extracorporeal membrane oxygenation (VA ECMO), the transition point at which the antegrade pulsatile output from the left ventricle and the retrograde non-pulsatile ECMO output collide is referred to as watershed [1]. Currently, no standard method is available to determine its location. Occasionally, contrast-enhanced computed tomography (CT) or angiography has been used [1-3]. Both techniques, however, bear disadvantages including radiation exposure and use of iodinated contrast media. We assessed the feasibility and safety of contrast-enhanced ultrasound (CEUS) to detect the watershed at the bedside in patients on bifemoral VA ECMO at three ICUs of a European tertiary care facility.

\section{Methods}

CEUS was performed as soon as possible after ECMOinitiation (Cardiohelp, Maquet, Germany) using SonoVue contrast media (Bracco, Italy). Transesophageal echocardiography ( $x 7-2 t$ probe) and transabdominal

\footnotetext{
* Correspondence: michael.schwameis@meduniwien.ac.at

${ }^{2}$ Department of Emergency Medicine, Medical University of Vienna, Währinger Gürtel 18-20, 1090 Vienna, Austria

Full list of author information is available at the end of the article
}

sonography (3-5 $\mathrm{MHz}$ curvilinear probe) were performed concomitantly to display mid-esophageal aortic valve, ascending, descending aorta, and upper esophageal aortic arch long-axis views as well as longitudinal views of the proximal (below diaphragm), mid (level of renal arteries), and distal (above iliac bifurcation) abdominal aorta. The mechanical index was set to $0.05-0.10$ field of view. Prior to CEUS, the arterial bubble sensor activating zero-flow mode was disabled. The acoustic alarm was kept active. The presence or absence of pulsatility in the left radial artery was documented.

One milliliter of SonoVue was administered via the venous drainage cannula, followed by a flush of $10 \mathrm{ml}$ normal saline. The obtained images were evaluated qualitatively. If a watershed area was not able to be visualized, contrast-enhanced blood flow was classified into "pulsatile" or "continuous" to discriminate between cardiac and ECMO blood flow. The feasibility of CEUS was assessed based on qualitative image evaluation, the amount of contrast media administered, and the rate of bubble detection. Secondary outcomes were safety and frequency of radial arterial pulsatility. Safety variables included ECMO settings, hemodynamics, and neurologic assessment and were obtained over a 6 -h period after CEUS. 
The variables are presented as absolute values $(n)$, relative frequencies (\%), and median (25-75\% IQR). We used random-effects general linear regression models to estimate mean changes for each safety variable (mean $\pm \mathrm{SD}$ ).

\section{Results}

Between August 2018 and April 2019, ten patients were enrolled (Table 1). Qualitative detection of watershed location by CEUS was feasible using $1 \mathrm{ml}$ contrast media. In five patients, the watershed could be clearly shown in the abdominal aorta, seconds after contrast media administration (Fig. 1). In the remaining five patients, contrast-enhanced continuous blood flow was visible throughout the abdominal and thoracic aorta indicating watershed location close to the aortic root. The pulsatility of the left radial arterial waveform and opening of the aortic valve was present in all patients. Acoustic bubble detection occurred in all patients after CEUS. No changes in the safety variables related to CEUS occurred (Table 1). CT imaging of the brain ( $8 / 10$ patients) showed no cerebral lesions suggesting particle embolism.

Table 1 Baseline characteristics and changes of safety variables from baseline to $6 \mathrm{~h}$ after contrast media application

\begin{tabular}{|c|c|c|c|c|c|}
\hline \multicolumn{6}{|l|}{ Baseline characteristics } \\
\hline \multicolumn{3}{|l|}{ Male sex } & \multicolumn{3}{|l|}{$9[90]$} \\
\hline \multicolumn{3}{|l|}{ Age (years) } & \multicolumn{3}{|l|}{$52(50-55)$} \\
\hline \multicolumn{6}{|l|}{ Reason for ECMO } \\
\hline \multicolumn{3}{|l|}{ Refractory cardiac arrest } & \multicolumn{3}{|l|}{$6[60]$} \\
\hline \multicolumn{3}{|l|}{ Cardiogenic shock } & \multicolumn{3}{|l|}{$4[40]$} \\
\hline \multicolumn{3}{|c|}{ Presence of severely impaired left ventricular systolic function } & \multicolumn{3}{|l|}{$10[100]$} \\
\hline \multicolumn{3}{|c|}{ Time from ECMO start to study inclusion (days), min to max } & \multicolumn{3}{|l|}{$0-1$} \\
\hline \multicolumn{3}{|l|}{ Successful ECMO weaning } & \multicolumn{3}{|l|}{$5[50]$} \\
\hline \multicolumn{3}{|l|}{ Good neurologic outcome (CPC 1-2) } & \multicolumn{3}{|l|}{$3[30]$} \\
\hline \multicolumn{3}{|c|}{ Post-oxygenator $\mathrm{paO}_{2}$ after contrast-enhanced ultrasound $(\mathrm{mmHg})$} & \multicolumn{3}{|l|}{$489(439-507)$} \\
\hline \multicolumn{6}{|l|}{ Safety parameters } \\
\hline Variable & Baseline $(n=10)$ & $5 \min (n=10)$ & $15 \min (n=10)$ & $2 \mathrm{~h}(n=9)$ & $6 \mathrm{~h}(n=8)$ \\
\hline Ventilator $\mathrm{FiO}_{2}(\%)$ & $48(40-80)$ & $48(40-80)$ & $48(40-80)$ & $55(45-80)$ & $48(40-70)$ \\
\hline Peak pressure (mbar) & $19.5(18-21)$ & $19(18-21)$ & $19(18-21)$ & $20(19-23)$ & $18(18-23)$ \\
\hline MAP $(\mathrm{mmHg})$ & $73(70-81)$ & 73 (64-93) & $73(64-93)$ & $77(73-82)$ & $82(74-94)$ \\
\hline Norepinephrine ( $\mu \mathrm{g} / \mathrm{kg} / \mathrm{min})$ & $0.34(0.209-0.670)$ & $0.250(0.148-0.480)$ & $0.250(0.148-0.480)$ & $0.420(0.190-0.620)$ & $0.410(0.142-0.715)$ \\
\hline Heart rate (bpm) & $97(66-111)$ & $91(64-107)$ & $90(64-107)$ & $80(61-105)$ & $95(72-107)$ \\
\hline Pump speed (rpm) & $2776(2530-3151)$ & $2698(2530-3000)$ & $2698(2530-3000)$ & $2741(2530-3000)$ & $3050(2590-3300)$ \\
\hline Blood flow (I/min) & $2.23(1.61-2.90)$ & $2.13(1.58-2.63)$ & $2.13(1.58-2.63)$ & $2.37(1.70-2.80)$ & $2.76(2.10-3.31)$ \\
\hline \multirow[t]{2}{*}{ New-onset pupil dilation and/or anisocoria } & 0 & 0 & 0 & 0 & 0 \\
\hline & SD overall & SD within & \multicolumn{2}{|c|}{$\begin{array}{l}\text { Mean change ( } 95 \% \text { confidence } \\
\text { interval) }\end{array}$} & $p$ value* \\
\hline Ventilator $\mathrm{FiO}_{2}(\%)$ & 23.72 & 8.59 & \multicolumn{2}{|l|}{$-3.39(-7.54$ to 0.75$)$} & 0.109 \\
\hline Peak pressure (mbar) & 3.71 & 1.11 & \multicolumn{2}{|l|}{$0.44(-0.63$ to 1.51$)$} & 0.420 \\
\hline MAP $(\mathrm{mmHg})$ & 13.32 & 8.31 & \multicolumn{2}{|l|}{$-1.03(-8.31$ to 6.25$)$} & 0.781 \\
\hline Norepinephrine ( $\mu \mathrm{g} / \mathrm{kg} / \mathrm{min})$ & 0.32 & 0.15 & \multicolumn{2}{|l|}{$-0.23(-0.18$ to 0.13$)$} & 0.774 \\
\hline Heart rate (bpm) & 25.84 & 5.68 & \multicolumn{2}{|c|}{$-0.87(-5.68$ to 3.93$)$} & 0.721 \\
\hline Pump speed (rpm) & 1305.51 & 159.90 & \multicolumn{2}{|c|}{$0.67(-86.46$ to 87.80$)$} & 0.988 \\
\hline Blood flow (I/min) & 0.84 & 0.41 & \multicolumn{2}{|l|}{$0.073(-0.15$ to 0.29$)$} & 0.512 \\
\hline
\end{tabular}

Data are $n$ [\%] or median (25-75\% IQR), unless indicated otherwise. For the random-effects general linear regression models, means with standard deviations were calculated. During the observation period, no changes in hemodynamic values, vasopressor dose, respirator, and ECMO settings occurred in temporal relationship to SonoVue administration. Two patients had already dilated pupils at the time of ultrasound study. Both patients died during the 6-h observation period following a decision to withdraw treatment by the treating physician

CPC cerebral performance category, ECMO extracorporeal membrane oxygenation, $\mathrm{FiO}_{2}$ fraction of inspired oxygen, MAP mean arterial pressure, SD standard deviation

*Results from random-effects general linear regression model 


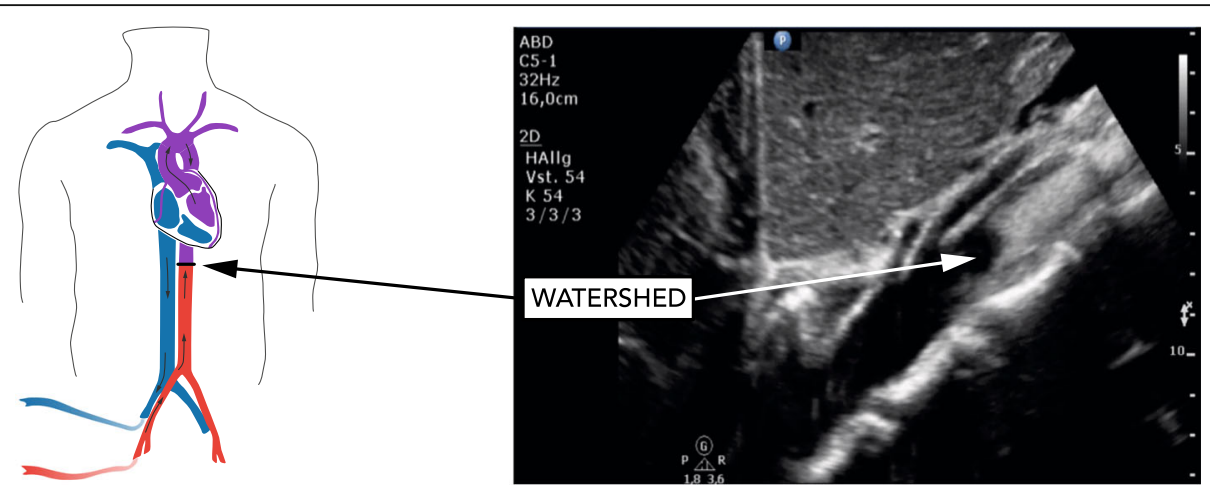

Fig. 1 Visualization of contrast-enhanced retrograde non-pulsatile ECMO blood flow. The watershed is marked with an arrow and located distal to the superior mesenteric artery

\section{Discussion}

This study assessed the feasibility of CEUS for watershed detection at the bedside in patients on bifemoral VA ECMO. CEUS was apparently safe and provided realtime assessment of the watershed or contrast-enhanced continuous blood flow in the aorta. Increasing evidence indicates that CEUS is safe in critically ill patients, and application areas are ever-expanding [4-6]. In bifemoral VA ECMO, CEUS may help to identify patients at risk for differential hypoxia, given that left radial arterial pulsatility was present in all study patients, including those in whom the watershed was located near the aortic root.

\section{Limitations}

Transthoracic suprasternal echocardiography may be useful to localize the watershed in the aortic arch but has not been tested. Furthermore, no reference imaging technique has been used to assess the performance of CEUS, because no standard method for the detection of the watershed is available, and no repeated measurements were performed.

\section{Abbreviations}

CEUS: Contrast-enhanced ultrasound; CT: Computed tomography; VA ECMO: Venoarterial extracorporeal membrane oxygenation

\section{Acknowledgements}

We gratefully thank our collaborators Gerhard Ruzicka, Christoph Weiser, Hans Domanovits, Alexander O. Spiel, Peter Schellongowski, Andja Bojic, Anne Merrelaar, and Monika Schmid for their valuable help with patient recruitment, performing ultrasound and study flow throughout the study. We thank Sarah Ely for the thorough revision of the manuscript.

\section{Authors' contributions}

NB, MS, and TS designed the study. NB, MS, CS, and AH enrolled the study patients and/or performed the ultrasound. NB, MS, and CS collected the data together with the trained study nurses. NB, MS, and TS analyzed and interpreted the data. $\mathrm{HH}$ did the statistical analysis. NB and MS wrote the first draft of the manuscript and drew the figure and table. All authors critically revised the manuscript for important intellectual content and approved its current version. All authors agreed to be accountable for all aspects of the work in ensuring that questions related to the accuracy or integrity of any part of the work are appropriately investigated and resolved. The manuscript has not been previously published and is not under consideration for publication in the same or substantially similar form in any other peerreviewed media.

\section{Funding}

This study was supported by the Austrian Society for Internal Medicine and General Intensive Care and Emergency Medicine (ÖGIAIN).

\section{Availability of data and materials}

The datasets analyzed during the current study are available from the corresponding author on reasonable request. Complete results from safety data are available with the main manuscript. Exemplary ultrasound loops are available from the corresponding author on request.

\section{Ethics approval and consent to participate}

The study was approved by the Ethics Committee of the Medical University of Vienna (EC\#1177/2018) and conducted in accordance with Helsinki Declarations. According to Austrian law regulations, prior to the study enrolment, a waiver was obtained and patients were informed about their participation after regaining consciousness.

\section{Consent for publication}

Not applicable

\section{Competing interests}

The authors declare that they have no competing interests.

\section{Author details}

${ }^{1}$ Department of Medicine I, Intensive Care Unit 13i2, Medical University of Vienna, Vienna, Austria. ${ }^{2}$ Department of Emergency Medicine, Medical University of Vienna, Währinger Gürtel 18-20, 1090 Vienna, Austria.

${ }^{3}$ Department of Clinical Pharmacology, Medical University of Vienna, Vienna, Austria.

Received: 3 March 2020 Accepted: 23 March 2020

Published online: 02 April 2020

\section{References}

1. Hoeper MM, Tudorache I, Kuhn C, Marsch G, Hartung D, Wiesner O, et al. Extracorporeal membrane oxygenation watershed. Circulation. 2014;130(10): 864-5.

2. Napp LC, Brehm M, Kuhn C, Schafer A, Bauersachs J. Heart against venoarterial ECMO: competition visualized. Int J Cardiol. 2015:187:164-5.

3. Lambert L, Grus T, Balik M, Fichtl J, Kavan J, Belohlavek J. Hemodynamic changes in patients with extracorporeal membrane oxygenation (ECMO) demonstrated by contrast-enhanced CT examinations - implications for image acquisition technique. Perfusion. 2017;32(3):220-5.

4. Bennett CE, Tweet MS, Michelena HI, Schears GJ, Mulvagh SL. Safety and feasibility of contrast echocardiography for ECMO evaluation. JACC Cardiovasc Imaging. 2017;10(5):603-4. 
5. Fine NM, Abdelmoneim SS, Dichak A, Kushwaha SS, Park SJ, Mulvagh SL. Safety and feasibility of contrast echocardiography for LVAD evaluation. JACC Cardiovasc Imaging. 2014;7(4):429-30.

6. Harrois A, Grillot N, Figueiredo S, Duranteau J. Acute kidney injury is associated with a decrease in cortical renal perfusion during septic shock. Crit Care. 2018;22(1):161

\section{Publisher's Note}

Springer Nature remains neutral with regard to jurisdictional claims in published maps and institutional affiliations.

Ready to submit your research? Choose BMC and benefit from:

- fast, convenient online submission

- thorough peer review by experienced researchers in your field

- rapid publication on acceptance

- support for research data, including large and complex data types

- gold Open Access which fosters wider collaboration and increased citations

- maximum visibility for your research: over $100 \mathrm{M}$ website views per year

At BMC, research is always in progress.

Learn more biomedcentral.com/submissions 